\title{
Low serum cholinesterase predicts complication risk after orthopedic surgery in elderly patients: an observational pilot study
}

Mitsuhiro Matsuo ${ }^{1 *}$ (D) and Tohru Yamagami²

\begin{abstract}
Background: Serum cholinesterase (ChE) in elderly adults is associated with geriatric conditions such as sarcopenia and malnutrition. The aim of this study is to examine the impact of preoperative serum ChE on the development of complications after noncardiac surgery in elderly patients without liver cirrhosis.

Methods: We retrospectively identified all patients aged $\geq 65$ years who underwent orthopedic surgery over a 1.5-year period in our hospital. The main outcome was postoperative complications, defined as a deviation from the normal postoperative course within 30 days postoperatively.

Results: A total of 313 patients (median age 79 years) were included. The incidence of all-cause postoperative complications was $15.7 \%$ (49/313 patients). Receiver operating characteristic curve analysis showed that serum ChE was a univariable factor that predicted all-cause complications with moderate accuracy (area under the curve $=0.694,95 \%$ confidence interval (CI) 0.604-0.783), with an optimal serum ChE cutoff level of 200 units/L. After multivariate analyses adjusted by baseline characteristics, low serum ChE remained a significant risk factor for postoperative complications (odds ratio $=2.99,95 \% \mathrm{Cl} 1.41-6.33, P=0.004$ ).

Conclusions: Low serum ChE ( $<200$ unit/L) is a significant risk factor for postoperative complications after orthopedic surgery in patients aged $\geq 65$ years.
\end{abstract}

Keywords: Aged, Frail elderly, Postoperative complications, Preoperative care, Risk assessment

\section{Introduction}

Pseudocholinesterase is a nonspecific cholinesterase $(\mathrm{ChE})$ that is produced by the liver and distributed to the whole body [1]. Pseudocholinesterase activity is represented by serum $\mathrm{ChE}$ in routine diagnostic tests, and serum $\mathrm{ChE}$ is a good biomarker for liver cirrhosis [2]. In patients with liver cirrhosis, decreased serum ChE predicts poor survival following cardiac $[3,4]$ and noncardiac surgery $[5,6]$. An increasing number of reports show that serum $\mathrm{ChE}$ in elderly adults is associated with geriatric conditions such as sarcopenia [7] and malnutrition $[8,9]$. However, little is known about the impact of

\footnotetext{
* Correspondence: matsuo@itoigawa-hp.jp

${ }^{1}$ Department of Anesthesiology, Itoigawa General Hospital, 457-1

Takegahana, Itoigawa, Niigata 941-8502, Japan

Full list of author information is available at the end of the article
}

preoperative serum ChE on the development of postoperative complications in elderly patients without liver disease.

Aging is characterized by a progressive and functional decline of all organ systems, which is associated with an increase in postoperative complications [10]. Thus, advanced age and frailty are independent risk factors for perioperative complications in noncardiac surgery such as orthopedics $[10,11]$. Our recent study showed that serum ChE decreases with age in physically independent individuals aged $\geq 65$ years [12]. Therefore, we hypothesized that ChE would act as a geriatric marker and predict the development of postoperative complications. To test this hypothesis, we examined the effect of preoperative $\mathrm{ChE}$ value on the postoperative 
complication rate in patients aged $\geq 65$ years who underwent orthopedic surgery.

\section{Methods Study design}

This retrospective cohort study was approved by the ethics committee of Itoigawa General Hospital (\#201818, 14 November 2018) and was conducted in accordance with the principles of the Declaration of Helsinki. We included all patients aged $\geq 65$ years who underwent orthopedic surgery in our hospital from April 2017 to September 2018. Patients who underwent repeat surgery within 2 months were excluded. ChE activity was determined using p-hydroxybenzoic acid as a substrate with a TBA-c16000 system (Canon Medical System Corp., Otawara, Japan). Serum ChE was routinely evaluated before orthopedic surgery in our hospital. The estimated glomerular filtration rate in milliliters per minute per $1.73 \mathrm{~m}^{2}$ was calculated from the creatinine concentration using the Japanese equation [13]. Anemia was defined as hemoglobin of $<10 \mathrm{~g} / \mathrm{dL}$. Patients with hypertension, dyslipidemia, and diabetes mellitus requiring medication were included. Patients diagnosed with liver cirrhosis or with a history of hepatocellular carcinoma were defined as having liver failure. End-stage renal disease was defined as an estimated glomerular filtration rate of $<15$ $\mathrm{mL} / \mathrm{min} / 1.73 \mathrm{~m}^{2}$ or the need for dialysis. The main outcome was postoperative complications, defined as a deviation from the normal postoperative course, such as the use of unscheduled antibiotics or a condition requiring specialist investigation within 30 days postoperatively. Major complications were defined as life-threatening diseases.

\section{Statistical analysis}

Data are shown as median [interquartile range]. The optimal cutoff level of ChE was determined by calculating the odds ratio (OR) for every 10 units/L in univariate analysis. Statistical comparisons were performed using the Mann-Whitney test and Fisher's exact test. A $P$ value of $<0.05$ was considered statistically significant. Logistic regression analysis was used to adjust all baseline characteristics that yielded $P$ values of $<0.05$. All statistical analyses were performed using EZR software [14].

\section{Results}

In total, 348 orthopedic surgeries were performed in patients aged $\geq 65$ years in our institute over a 1.5 -year period. Preoperative serum ChE was not evaluated in 24 patients, and 11 patients were excluded because of reoperation or debridement related to prior surgery. Thus, the remaining 313 patients were included, and the characteristics are summarized in Table 1 . All patients were Japanese (median age 79 [72-86] years). No malignant tumor removal was performed during the study period. Although seven patients had liver failure, none had severe cirrhosis classified as Child-Pugh class C. Preoperative $\mathrm{ChE}$ in all patients was 267 [221-325] unit/L.

All-cause complications within 30 days postoperatively developed in 49 of 313 patients (15.7\%; Tables 1,2). The preoperative serum $\mathrm{ChE}$ in patients with all-cause complications was significantly lower than that in patients without any complications (222 [178-274] unit/L vs 272 [234-329] unit/L; $P<0.001)$. Two patients $(0.6 \%)$ died within 30 days postoperatively; they were 80 - and 84 year-old women with acute myocardial infarction and preoperative ChE values of 265 and 260 unit/L, respectively. The preoperative serum ChE in patients with major complications was significantly lower than that in patients without major complications (207 [136-260] unit/L vs 267 [223-327] unit/L; $P=0.008$ ).

Receiver operating characteristic curve analysis showed that serum ChE predicted all-cause complications as a univariable factor with moderate accuracy (area under the curve $=0.694,95 \%$ confidence interval [CI] 0.604-0.783). The optimal cutoff level of serum ChE was calculated as 200 units/L with a sensitivity of $41.2 \%$ and specificity of $86.3 \%$, and the OR was 5.33 (95\% CI 2.74-10.4, $P<0.001$; Table 3). Significant baseline characteristics in Table 1 were used in the logistic regression analysis; age, body mass index, American Society of Anesthesiologists (ASA) class $\geq 3$, a history of heart disease, operative indication, and perioperative blood transfusion. After adjustment, low serum ChE remained a significant risk factor for postoperative complications with the OR of 2.99 (95\% CI 1.41-6.33, $P=$ 0.004; Table 3).

\section{Discussion}

In the present study, we examined the association between preoperative serum $\mathrm{ChE}$ and the development of postoperative complications in orthopedic patients aged $\geq 65$ years. After adjustment for possible confounding factors, low serum $\mathrm{ChE}$ was a significant risk factor for the occurrence of complications within 30 days postoperatively. These data suggest that consideration of the preoperative serum $\mathrm{ChE}$ will enable anesthesiologists and surgeons to improve risk stratification for elderly orthopedic patients.

Serum ChE activity itself is not likely to have a direct effect on the occurrence of postoperative complications. Increasing evidence shows that serum ChE in elderly adult patients is an adverse prognostic factor in conditions other than liver disease, such as bladder cancer [15], coronary artery disease $[16,17]$, heart failure [18], peripheral artery disease [19], and systemic inflammatory response syndrome [20]. In the present study, multivariate analyses showed that the influence of low serum ChE 
Table 1 Characteristics of orthopedic surgery patients in this study

\begin{tabular}{lllll}
\hline & & \multicolumn{2}{l}{$\begin{array}{l}\text { Postoperative } \\
\text { complications }\end{array}$} \\
& Total & Yes & No & $P$ value \\
\hline Number & 313 & 49 & 264 &
\end{tabular}

Age, years

$\begin{array}{cllll}65-74 \text { years } & 95 & 9 & 86 & \\ 75-89 \text { years } & 171 & 26 & 145 & 0.011 \\ \geq 90 \text { years } & 47 & 14 & 33 & \\ \text { Gender, female } & 221 & 29 & 192 & 0.062\end{array}$

BMl, $\mathrm{kg} / \mathrm{m}^{2}$

$$
\begin{gathered}
\quad 18.5-24.9 \mathrm{~kg} / \mathrm{m}^{2} \\
<18.5 \mathrm{~kg} / \mathrm{m}^{2} \\
>25.0 \mathrm{~kg} / \mathrm{m}^{2} \\
\text { Comorbidities }
\end{gathered}
$$

$$
\text { Anemia }
$$

Hypertension

Dyslipidemia

Diabetes mellitus

ASA class $\geq 3$

Glucocorticoids use

Organ impairment

COPD requiring medication

History of HF or IHD

Liver failure

ESRD

Operative indication

Upper limb fracture
Lower limb fracture
Spinal/pelvic fracture
Osteoarthritis
Spinal surgery
Others

Surgical procedure

Operative time $\geq 2 \mathrm{~h}$

Bleeding volume $\geq 500 \mathrm{~mL}$

Emergency

Anesthetic procedure

\begin{tabular}{|c|c|c|c|c|}
\hline & \multirow[b]{2}{*}{ Total } & \multicolumn{2}{|c|}{$\begin{array}{l}\text { Postoperative } \\
\text { complications }\end{array}$} & \multirow[b]{2}{*}{$P$ value } \\
\hline & & Yes & No & \\
\hline Epidural analgesia & 7 & 0 & 7 & \\
\hline Perioperative blood transfusion & 68 & 19 & 49 & 0.004 \\
\hline \multicolumn{5}{|c|}{$\begin{array}{l}\text { Statistical comparisons were performed using the Fisher's exact test. ASA } \\
\text { American Society of Anesthesiologists, COPD chronic obstructive pulmonary } \\
\text { disease, DM diabetes mellitus, eGFR estimated glomerular filtration rate, ESRD } \\
\text { end-stage renal disease, HF heart failure, HTN hypertension, IHD ischemic heart } \\
\text { disease, PCA patient-controlled analgesia }\end{array}$} \\
\hline
\end{tabular}

Spinal
General
Postoperative analgesia
Parenteral analgesics as needed
Peripheral nerve blocks
PCA
PCA combined with nerve blocks

PCA combined with nerve blocks
Table 1 Characteristics of orthopedic surgery patients in this study (Continued)

on postoperative complications did not depend on liver function (Table 3). Serum ChE is associated with frailty conditions, such as sarcopenia [7], malnutrition [8, 9], and body weight loss [21]. The present findings further support the use of $\mathrm{ChE}$ as a comprehensive geriatric marker. Additionally, sarcopenia [22] and malnutrition $[23,24]$ are related to the development of postoperative complications. As low serum ChE is useful as a surrogate marker of geriatric frailty, low serum ChE may be a useful predictor of complications following procedures other than orthopedic surgery in elderly adult patients.

In the present study, the cutoff value of serum $\mathrm{ChE}$ was obtained with an optimal OR in univariate analysis. The cutoff level for ChE of 200 units/L was the same as that reported in a previous study that showed that decreased ChE predicts postoperative survival in lung cancer patients with liver cirrhosis [5]. In the present study, the cutoff level for serum ChE of 200 units/L provided a high specificity $(86.3 \%)$ but low sensitivity $(41.2 \%)$ in predicting postoperative complications. In fact, the average serum ChE was $204 \pm 80$ units/L in patients with

Table 2 Complications within 30 days after orthopedic surgery

\begin{tabular}{ll}
\hline & $n=49$ \\
\hline Major complications, $n=11$ & 4 \\
Heart failure & 3 \\
Myocardial infarction & 2 \\
Cerebral infarction & 2 \\
Pulmonary embolism & \\
Minor complications, $n=38$ & 9 \\
Urinary tract infection & 4 \\
Pneumonia & 3 \\
Surgical site infection & 3 \\
Calcium pyrophosphate deposition disease & 2 \\
Deep vein thrombosis in the lower leg & 2 \\
Sick sinus syndrome & 2 \\
Cellulitis & 13 \\
Others (acute kidney injury, bleeding peptic ulcer, \\
cholangitis, etc.)
\end{tabular}


Table 3 Impact of low cholinesterase on predicting the development of complications after orthopedic surgery

\begin{tabular}{llllll}
\hline & Unadjusted & & & Adjusted & \\
\cline { 2 - 3 } & OR $(95 \% \mathrm{Cl})$ & $P$ value & & OR $(95 \% \mathrm{Cl})$ & $P$ value \\
\hline Serum ChE, & $5.33(2.74-10.4)$ & $<0.001$ & & $2.99(1.41-6.33)$ & 0.004 \\
$<200$ unit/L & & & &
\end{tabular}

Logistic regression analysis was used to adjust age, body mass index, American Society of Anesthesiologists class $\geq 3$, history of heart failure or ischemic heart disease, operative indication, and perioperative blood transfusion. ChE cholinesterase, $O R$ odds ratio

major complications, and the two dead patients had serum ChE levels of $\geq 200$ units/L. Thus, low serum $\mathrm{ChE}$ may be a useful marker with which to identify, but not exclude, high-risk patients prior to surgery.

A major limitation of the present study is that no nutritional assessment was performed, although a few patients had severe organ failure that may have caused malnutrition. Moreover, perioperative cognitive function was not assessed [25], as it was difficult to define these diagnoses in this historical medical record review. ChE value is also affected by sarcopenia [7]. However, it was impossible to perform preoperative sarcopenic assessment, such as gait speed and handgrip strength [26], as the reason for surgery was fracture in most patients. In this study, we regarded a deviation from the normal postoperative course as postoperative complications. Although our definition of postoperative complications provided an objective threshold to evaluate in this chart review study, we cannot rule out the possibility that the definition resulted in an overestimation of postoperative complications. Finally, the present study included a small number of patients and was performed in a single institute. The present findings require confirmation in prospective multicenter studies.

\section{Conclusion}

Preoperative low serum ChE predicted the development of complications after orthopedic surgery in elderly adult patients. Further studies are needed to elucidate the precise mechanism by which low serum ChE causes the development of postoperative complications.

\section{Abbreviations}

ASA: American Society of Anesthesiologists; ChE: cholinesterase; Cl: confidence interval; OR: odds ratio

\section{Acknowledgements}

None.

\section{Authors' contributions}

MM designed and performed the research and $Y T$ supervised the manuscript preparation. Both authors read and approved the final manuscript.

\section{Funding}

The authors declare that they received no funding for this work.

\section{Availability of data and materials}

The datasets used and/or analyzed during the current study are available from the corresponding author on reasonable request.

\section{Ethics approval and consent to participate}

This retrospective cohort study was approved by the ethics committee of Itoigawa General Hospital (\#2018-18) and was conducted in accordance with the principles of the Declaration of Helsinki.

\section{Consent for publication}

As this study was conducted in a retrospective manner, we did not obtain consent for publication from the participants.

\section{Competing interests}

The authors declare that they have no competing interests.

\section{Author details}

'Department of Anesthesiology, Itoigawa General Hospital, 457-1

Takegahana, Itoigawa, Niigata 941-8502, Japan. ${ }^{2}$ Department of Orthopedic Surgery, Itoigawa General Hospital, Itoigawa, Niigata, Japan.

Received: 8 May 2019 Accepted: 7 June 2019

Published online: 14 June 2019

\section{References}

1. Robles A, Michael M, McCallum R. Pseudocholinesterase deficiency: what the proceduralist needs to know. Am J Med Sci. 2019;357:263-7.

2. Ramachandran J, Sajith KG, Priya S, Dutta AK, Balasubramanian KA. Serum cholinesterase is an excellent biomarker of liver cirrhosis. Trop Gastroenterol. 2014:35:15-20.

3. An Y, Xiao YB, Zhong QJ. Open-heart surgery in patients with liver cirrhosis: indications, risk factors, and clinical outcomes. Eur Surg Res. 2007;39:67-74.

4. Murashita T, Komiya T, Tamura N, Sakaguchi G, Kobayashi T, Furukawa T, Matsushita A, Sunagawa G. Preoperative evaluation of patients with liver cirrhosis undergoing open heart surgery. Gen Thorac Cardiovasc Surg. 2009; 57:293-7.

5. Iwata T, Inoue K, Nishiyama N, Nagano K, Izumi N, Mizuguchi S, Morita R, Tsukioka T, Suehiro S. Long-term outcome of surgical treatment for nonsmall cell lung cancer with comorbid liver cirrhosis. Ann Thorac Surg. 2007; 84:1810-7.

6. Weismüller TJ, Prokein J, Becker T, Barg-Hock H, Klempnauer J, Manns MP, Strassburg CP. Prediction of survival after liver transplantation by pre-transplant parameters. Scand J Gastroenterol. 2008;43:736-46.

7. Cacciatore F, Della-Morte D, Basile C, Curcio F, Liguori I, Roselli M, Gargiulo G, Galizia G, Bonaduce D, Abete P. Butyryl-cholinesterase is related to muscle mass and strength. A new biomarker to identify elderly subjects at risk of sarcopenia. Biomark Med. 2015;9:669-78.

8. Schreiber FS, Becker I, Deckert P, Elsbernd H, Isensee C. Malnutrition and laboratory markers in geriatric patients. A comparison of neurologicpsychiatric, internal and trauma surgical diseases. J Nutr Health Aging. 2016;20:458-61

9. Santarpia L, Grandone I, Contaldo F, Pasanisi F. Butyrylcholinesterase as a prognostic marker: a review of the literature. J Cachexia Sarcopenia Muscle. 2013:4:31-9.

10. Eamer G, Al-Amoodi MJH, Holroyd-Leduc J, Rolfson DB, Warkentin LM, Khadaroo RG. Review of risk assessment tools to predict morbidity and mortality in elderly surgical patients. Am J Surg. 2018;216:585-94.

11. Matsuo M, Yamagami T, Higuchi A. Impact of age on postoperative complication rates among elderly patients with hip fracture: a retrospective matched study. J Anesth. 2018;32:452-6.

12. Matsuo M, Tazawa K. Reference range of clinical blood tests in physically independent patients of advanced age with groin hernia in a Japanese hospital. Geriatr Gerontol Int. https://doi.org/10.1111/ggi.13712.

13. Matsuo S, Imai E, Horio M, Yasuda Y, Tomita K, Nitta K, Yamagata K, Tomino Y, Yokoyama H, Hishida A. Collaborators developing the Japanese equation for estimated GFR. Revised equations for estimated GFR from serum creatinine in Japan. Am J Kidney Dis. 2009;53:982-92.

14. Kanda Y. Investigation of the freely available easy-to-use software 'EZR' for medical statistics. Bone Marrow Transplant. 2013;48:452-8.

15. Koie T, Ohyama C, Yamamoto $H$, Hatakeyama S, Imai A, Yoneyama T, Hashimoto Y, Kitayam M, Hirota K. Significance of preoperative 
butyrylcholinesterase as an independent predictor of survival in patients with muscle-invasive bladder cancer treated with radical cystectomy. Urol Oncol. 2014;32:820-5.

16. Goliasch G, Kleber ME, Richter B, Plischke M, Hoke M, Haschemi A, Marculescu R, Endler G, Grammer TB, Pilz S, Tomaschitz A, Silbernagel G, Maurer G, Wagner O, Huber K, März W, Mannhalter C, Niessner A. Routinely available biomarkers improve prediction of long-term mortality in stable coronary artery disease: the Vienna and Ludwigshafen Coronary Artery Disease (VILCAD) risk score. Eur Heart J. 2012;33:2282-9.

17. Goliasch G, Haschemi A, Marculescu R, Endler G, Maurer G, Wagner O, Huber K, Mannhalter C, Niessner A. Butyrylcholinesterase activity predicts longterm survival in patients with coronary artery disease. Clin Chem. 2012; 58:1055-8.

18. Sato T, Yamauchi H, Suzuki S, Yoshihisa A, Yamaki T, Sugimoto K, Kunii H, Nakazato K, Suzuki H, Saitoh S, Takeishi Y. Serum cholinesterase is an important prognostic factor in chronic heart failure. Heart Vessel. 2015;30: 204-10.

19. Gremmel T, Wadowski PP, Mueller M, Kopp CW, Koppensteiner R, Panzer S. Serum cholinesterase levels are associated with 2-year ischemic outcomes after angioplasty and stenting for peripheral artery disease. J Endovasc Ther. 2016;23:738-43.

20. Jin QH, He XJ, Li TL, Chen HH. Predictive value of serum cholinesterase for the prognosis of aged patients with systemic inflammatory response syndrome. Chin Med J. 2011;124:2692-5.

21. Oda E. Serum cholinesterase is inversely associated with body weight change in men undergoing routine health screening. Intern Med. 2015;54: 2427-32.

22. Bokshan SL, DePasse JM, Daniels AH. Sarcopenia in orthopedic serum surgery. Orthopedics. 2016;39:e295-300.

23. Wilson J, Lunati M, Grabel Z, Staley C, Schwartz AM, Schenker M. Hypoalbuminemia is an independent risk factor for 30-day mortality, postoperative complications, readmission, and reoperation in the operative lower extremity orthopedic trauma patient. J Orthop Trauma. 2019. https://doi.org/10.1097/BOT.0000000000001448.

24. Luchetti TJ, Chung A, Olmscheid N, Bohl DD, Hustedt JW. Hypoalbuminemia is associated with increased postoperative mortality and complications in hand surgery. Hand (N Y). 2019. https://doi.org/10.1177/1558944718820959.

25. Müller A, Olbert M, Heymann A, Zahn PK, Plaschke K, von Dossow V, Bitzinger D, Barth E, Meister M, Kranke P, Herrmann C, Wernecke KD, Spies $\mathrm{CD}$. Relevance of peripheral cholinesterase activity on postoperative delirium in adult surgical patients (CESARO): a prospective observational cohort study. Eur J Anaesthesiol. 2019;36:114-22.

26. Chen LK, Liu LK, Woo J, Assantachai P, Auyeung TW, Bahyah KS, Chou MY, Chen LY, Hsu PS, Krairit O, Lee JS, Lee WJ, Lee Y, Liang CK, Limpawattana P, Lin CS, Peng LN, Satake S, Suzuki T, Won CW, Wu CH, Wu SN, Zhang T, Zeng P, Akishita M, Arai H. Sarcopenia in asia: consensus report of the Asian Working Group for sarcopenia. J Am Med Dir Assoc. 2014;15:95-101.

\section{Publisher's Note}

Springer Nature remains neutral with regard to jurisdictional claims in published maps and institutional affiliations.

\section{Submit your manuscript to a SpringerOpen ${ }^{\circ}$ journal and benefit from:}

- Convenient online submission

- Rigorous peer review

- Open access: articles freely available online

- High visibility within the field

- Retaining the copyright to your article

Submit your next manuscript at $\boldsymbol{\nabla}$ springeropen.com 